(C) 2020 by the Arizona Board of Regents on behalf of the University of Arizona. This is an Open Access article, distributed under the terms of the Creative Commons Attribution licence (http://creativecommons. org/licenses/by/4.0/), which permits unrestricted re-use, distribution, and reproduction in any medium, provided the original work is properly cited.

\title{
RECENT DEVELOPMENTS IN CALIBRATION FOR ARCHAEOLOGICAL AND ENVIRONMENTAL SAMPLES
}

\author{
J van der Plicht ${ }^{1 *}$ (D) $\cdot$ C Bronk Ramsey ${ }^{2}$ (D) $\cdot \mathrm{T} \mathrm{J} \mathrm{Heaton}^{3} \cdot \mathrm{E} \mathrm{M} \mathrm{Scott}^{4}$ (i) $\cdot \mathrm{S}$ Talamo $^{5}$ \\ ${ }^{1}$ Center for Isotope Research, Groningen University, Nijenborgh 6, 9747 AG Groningen, The Netherlands \\ ${ }^{2}$ School of Archaeology, University of Oxford, 1 South Parks Rd., Oxford OX1 3TG, UK \\ ${ }^{3}$ School of Mathematics and Statistics, University of Sheffield, Sheffield S3 7RH, UK \\ ${ }^{4}$ School of Mathematics and Statistics, University of Glasgow, Glasgow G12 8QQ, Scotland \\ ${ }^{5}$ Department of Chemistry, University of Bologna, Via Selmi 2, I-40126 Bologna, Italy
}

\begin{abstract}
The curves recommended for calibrating radiocarbon $\left({ }^{14} \mathrm{C}\right)$ dates into absolute dates have been updated. For calibrating atmospheric samples from the Northern Hemisphere, the new curve is called IntCal20. This is accompanied by associated curves SHCal20 for the Southern Hemisphere, and Marine20 for marine samples. In this "companion article" we discuss advances and developments that have led to improvements in the updated curves and highlight some issues of relevance for the general readership. In particular the dendrochronological based part of the curve has seen a significant increase in data, with single-year resolution for certain time ranges, extending back to 13,910 calBP. Beyond the tree rings, the new curve is based upon an updated combination of marine corals, speleothems, macrofossils, and varved sediments and now reaches back to 55,000 calBP. Alongside these data advances, we have developed a new, bespoke statistical curve construction methodology to allow better incorporation of the diverse constituent records and produce a more robust curve with uncertainties. Combined, these data and methodological advances offer the potential for significant new insight into our past. We discuss some implications for the user, such as the dating of the Santorini eruption and also some consequences of the new curve for Paleolithic archaeology.
\end{abstract}

KEYWORDS: calibration, curve construction, IntCal, Paleolithic, Thera.

\section{INTRODUCTION}

The main backbone of radiocarbon $\left({ }^{14} \mathrm{C}\right)$ calibration has been and will continue to be tree rings dated by dendrochronology, for the time periods where this is possible. Thanks to the work of a large community of scientists in extending our dendrochronological record and generating new ${ }^{14} \mathrm{C}$ measurements, calibration has come a long way since the original curves constructed decades ago (Ralph et al. 1973; Suess 1980; Pearson and Stuiver 1986; Stuiver and Pearson 1986). In the early days, the ${ }^{14} \mathrm{C}$ data were mainly obtained from conventional laboratories specializing in high-precision dating (defined as $2 \%$ at the time). These were Belfast, Heidelberg, Groningen, Pretoria, Tucson, and Seattle; these laboratories also organized mutual intercomparisons at that time (Kromer et al. 1996). Today, with IntCal20, the dendro-based calibration curve extends back to 13,910 calBP $^{1}$ (11,960 calBC), with further extensions to 55,000 calBP from other records. Furthermore, large sections of the timescale have been redated using AMS.

Providing a calibration curve beyond our knowledge of dendrochonologically dated tree rings has proved a significant challenge. For the glacial part of the ${ }^{14} \mathrm{C}$ dating range, the first tentative "calibration curves" were based on very few observations, hence were highly coarse and lacking in detail. For example, Vogel and Kronfeld (1997) based their curve on only 20 paired ${ }^{14} \mathrm{C}$ and U/Th speleothem observations covering the past 50,000 years. However, during the past few decades, considerable progress has been made. Since the advent of AMS, calibration has been extended gradually to 55,000 years, i.e. the complete dating range, enabled by small

\footnotetext{
*Corresponding author. Email: J.van.der.Plicht@rug.nl

${ }^{1}$ While tree-ring measurements extending further back in time to 14,189 calBP are present in IntCal20, they are used alongside data from other records to estimate the curve beyond 13,910 calBP.
} 
samples provided by chronological records other than tree rings. The first dataset spanning the complete ${ }^{14} \mathrm{C}$ dating range was based on varves, i.e. laminated sediments from Lake Suigetsu (Kitagawa and van der Plicht 1998) and further datasets from other archives followed soon thereafter (Beck et al. 20012; Hughen et al. 2004; Fairbanks et al. 2005). However, these different records were clearly inconsistent over the oldest part of the ${ }^{14} \mathrm{C}$ dating range, 26-50 ka calBP (van der Plicht 2004) and very considerable uncertainties remained (Mellars 2006). For this reason, IntCal04 (Reimer et al. 2004) terminated at 26 $\mathrm{ka}$, and no internationally agreed, unified recommendation was made for calibration beyond that age (NotCa104; van der Plicht et al. 2004). Instead, radiocarbon users who did wish to calibrate beyond this range were required to select between a wide number of different calibration curves (Weninger and Jöris 2004; Fairbanks et al. 2005; van Andel 2005; Bronk Ramsey et al. 2006) based on the various individual datasets, and archives, available. This situation made direct comparability of published "calibrated" ages between studies difficult since potentially different calibration curves had been used to calibrate the underlying radiocarbon ages.

Once the reasons for some of the disparities in the datasets became better understood, the IntCal09 calibration curve (Reimer et al. 2009) was constructed and released to the community. This curve was derived from atmospheric and marine datasets (in particular from the Cariaco basin; Hughen et al. 2006) and corrected for estimated reservoir effects. The IntCa109 curve represented our best estimate of Northern Hemispheric atmospheric ${ }^{14} \mathrm{C}$ at that time. Nevertheless, disparities still remained between this estimate and the only true atmospheric data available of Lake Suigetsu (Kitagawa and van der Plicht 2000), suggesting issues remained to be resolved. Between 2009 and 2013, new records became available, in particular from speleothems (Hulu Cave; Southon et al. 2012) and laminated sediments (Lake Suigetsu; Bronk Ramsey et al. 2012). The IntCal13 calibration curve incorporated the information from all of this new data while retaining the information on which IntCal09 was based (Reimer et al. 2013).

The new IntCal20 (Reimer et al. 2020 in this issue) is the latest update and revision to the Northern Hemisphere calibration curve. It uses a new statistical methodology (Heaton et al. 2020a in this issue) throughout which offers more flexibility in modeling and hence an improved ability to combine the varied, and unique, constituent records. In the older time period, it is based upon new insights on various chronologies, most significantly for the Pleistocene (Cheng et al. 2018); and improved modeling of marine reservoir effects. We therefore hope IntCal20 moves us further towards resolving the challenges in synthesizing the various archives over this period. Further, the dendrochronological part of the IntCal20 calibration curve is also significantly improved. For example, the dataset for Kauri wood is extended during the Late Glacial (Hogg et al. 2016, 2020 in this issue). It is noteworthy to mention that, in total, IntCal13, the previous calibration curve, was based on 7019 raw measurements; for IntCal20, this number is 12,904 .

The work has been revolutionized by measurements using the newly developed MICADAS AMS machines, which are extremely efficient and deliver high-precision dates (Synal et al. 2007). Advances in measurement efficiency and enhanced precision will continue to improve the calibration curve further in the coming years (e.g. Balter 2006). Annual resolution, dendro-dated, tree ring ${ }^{14} \mathrm{C}$ determinations are being produced at high speed,

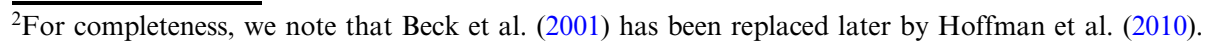


instigated by the hunt for so-called Miyake events, which are narrow spikes (subannual) of increased ${ }^{14} \mathrm{C}$ production (Miyake et al. 2012, 2013). In IntCal20, for the first time, these spike events have been specifically incorporated into the curve construction methodology better enabling their retention in the final calibration product (see below for more details). Further, the explosion of annual tree ring data has been incorporated into the curve via the new construction method which also recognizes that other ${ }^{14} \mathrm{C}$ measurements arise from multiple years, commonly decadal, blocks of tree rings.

The present and upcoming single year series therefore enable fine-tuning of the calibration curve for the Holocene and Late Glacial time periods. These high temporal resolution data, improved accuracy in the statistical construction method, and the new records have shown that adjustments to IntCal13 are needed. These adjustments may be significant for the interpretation of major events in the past: e.g. the Minoan Santorini/Thera eruption, a crucial time marker for archaeology in the second millennium $\mathrm{BC}$.

As a historical note, we observe that the ${ }^{14} \mathrm{C}$ dating method has revolutionized several disciplines, in particular archaeology. As put forward by Renfrew (1999), the first revolution was that samples could be dated by a scientific method at all; the second revolution was that calibration turned ${ }^{14} \mathrm{C}$ dates into absolute (calendar) dates. One may add that Bayesian analysis is often mentioned as a third revolution because it enables dating to decades, i.e. the scale of a human lifetime (Bayliss 2009). The calibration curve lies at the foundation of ${ }^{14} \mathrm{C}$ dating. It is ideally based on dendrochronology, which provides absolute dates with an annual resolution. Present developments, in particular, a mass of new dates on tree rings, enable further fine-tuning and corrections, as will be discussed in the examples below. The shape of the curve modeled through the measured ${ }^{14} \mathrm{C}$ data is also becoming more relevant, as we start on the road towards an annual highprecision calibration curve.

The above applies to dendrochronological records, which provide atmospheric/terrestrial calibration. Beyond the presently available tree-ring record (i.e. older than 13,910 calBP), calibration needs to be performed on data produced using other dating methods. There are several methods available, each with their own "pros and cons" (see the list in van der Plicht 2000). Major calibration records beyond the tree-ring timescale have become available, such as the varved sediments in Lake Suigetsu (Bronk Ramsey et al. 2012) and, most recently, Hulu Cave (Cheng et al. 2018). Remarkable progress has been made in recent years, but new data and insights frequently require changes in the calibration curve. True absolute dating remains work in progress.

This article is an update to the previous "companion" paper to IntCal13 (Bronk Ramsey et al. 2013), highlighting new developments and implications for the radiocarbon user community. We split our discussion into two sections. First, we present a broad overview of recent developments in our understanding of radiocarbon data and provide an intuitive explanation of the updated methodology used in the construction of IntCal20. Secondly, we provide several detailed and specific illustrations of calibration using the updated IntCal20 curves as opposed to IntCal13. While being of scientific interest in their own right, these examples have been chosen to illustrate several of the general features calibration users should expect to observe with their own calibrations, such as increased frequency of multi-modality in calibrated ages. In particular, we consider the consequences for the dating of the Minoan Santorini eruption, the Pleistocene/Holocene transition, and 
the replacement of Neanderthals by early Homo sapiens in the Paleolithic but the emphasis in this paper is to demonstrate some of the important practical changes arising from the IntCal20 developments.

\section{DEVELOPMENTS IN DATA AND THE CALIBRATION CURVE}

\section{Data and Understanding Uncertainties}

A key component for reliable radiocarbon calibration is the quantification and modeling of uncertainty, as well as how we approach data from different laboratories, different trees, different regions, and different environmental compartments. This is critical both for the construction of a robust IntCal20 curve and later calibration against it. We use the word uncertainty rather than error since it more correctly captures the natural variations that we are concerned with. Simply put every ${ }^{14} \mathrm{C}$ measurement comes with a measure of uncertainty (estimated by the laboratory) which must be incorporated into the curve fitting and calibration procedures. The better we can understand and represent this uncertainty the more reliable the calibration process.

Historically, from radiometric days, the quoted error was provided by the laboratory taking into account the internal measurement processes only. When an assemblage of dates is then formed, it frequently becomes apparent that the scatter in the results from the individual laboratory is greater than had been imagined given the quoted uncertainties on the individual measurements. This can be tackled in a variety of ways; one common approach that has historically been used is the error multiplier. E.g. in Stuiver (1982): "Analysis of the Seattle data sets and comparison with those published by the Belfast, La Jolla, and Heidelberg laboratories show that the total variability in a radiocarbon age determination is often larger than that predicted from the quoted errors. Upper limits for the error multiplier (i.e. the factor with which the quoted error has to be multiplied to obtain the overall laboratory variability) are estimated at 1.5 for Seattle and Belfast, 1.1 to 1.4 for La Jolla, and 2.0 for Heidelberg."

When we bring together data from different laboratories (dating the same samples), or for example, from the same laboratory measuring different trees (perhaps different species or grown in different regions) but covering the same time period, we will naturally see an additional variation, i.e. ${ }^{14} \mathrm{C}$ measurements in rings, with the identical calendar date, will not be identical. This could be characterized as an additional level of uncertainty or variation. We need to be careful in considering how we deal with this additional variation since some components may be systematic (sometimes described as an offset), and some will be stochastic. We can consider modeling this variation in terms of offsets and/or error multipliers (ISG 1982, 1983).

Characterizing these sources of variation is an essential part of the IntCal20 modeling approach since they impact both on the smoothness and/or wiggliness of the resulting curve and its uncertainty envelope. They also have the potential to affect how we calibrate against the IntCal20 curve, as we discuss later on calibration in the case of potential regional offsets.

One contributing element to quantifying variation is the practice that the ${ }^{14} \mathrm{C}$ community has adopted of organizing and participating in laboratory inter-comparisons. The general laboratory inter-comparisons have been open to all laboratories and have used a wide variety of routinely dated materials (including but not limited to tree-rings) (Scott et al. 2018). The 
information gained from these studies informed the choice of both model on the offsets and the prior on the level of additional variation incorporated in IntCal20 construction (Heaton et al. 2020a this issue). At the same time, more focal intercomparisons have refined estimation of the additional variation based solely on tree-rings (Wacker et al. 2020 in this issue) and on much smaller subsets of laboratories.

The improvements in the new generation of calibration curves are based on a number of related developments. A significant factor has been the newer generation of AMS machines. These provide improved precision beyond that routinely obtained in many laboratories and have delivered a wealth of single tree ring data. In combination, this has allowed some of the previously invisible structures in the historic level of atmospheric ${ }^{14} \mathrm{C}$ to be revealed that was not apparent when considering decadal or bidecadal samples. At the same time, more records are being considered in the creation of the calibration curve. This makes even more important the appropriate quantification of the sources of uncertainty since, without this, we run the risk of delivering an unrealistically precise calibration curve. Looking to the future, the calibration process will have to take account of any additional differences that might reasonably be expected between the calibration curve itself and measurements on samples which are inherently different from deciduous wood, and by methods that are also different.

\section{Construction of the IntCal20 Curve}

In addition to a database of radiocarbon determinations, each with an independently obtained calendar age and for which all the various uncertainties have been appropriately quantified, we also require a reliable approach to bring these measurements together to create the IntCal20 curve. We aim to do this in such a way that we retain all the genuine features of the radiocarbon record but remove any spurious variation in the raw observations. This is made more complex since some of the ${ }^{14} \mathrm{C}$ determinations have an uncertainty on their associated calendar age e.g. objects for which calendar ages are estimated by U/Th dating such as corals and speleothems; by varve counting or paleoclimate tuning as in the case of marine cores; or in the case of some floating tree-ring sequences uncertainty in the absolute dendrochronological age.

We achieve this via non-parametric regression whereby we place very few underlying assumptions about the nature of past ${ }^{14} \mathrm{C}$ beyond assuming a certain level of smoothness over time that allows us to borrow strength/information from the neighboring ${ }^{14} \mathrm{C}$ determinations (i.e. those of a similar calendar age) in estimating the curve. In essence, this approach is similar in spirit to a moving average process.

For IntCal20, we use Bayesian splines with errors-in-variables to implement this regression, a significant change from the random walk approach used in IntCa109 and IntCal13. We believe this switch to Bayesian splines provides several benefits allowing us to more accurately represent many of the unique aspects of the radiocarbon data and to test robustness to data and model assumptions. Maintaining the Bayesian paradigm in construction still allows us to incorporate any prior knowledge about the data, or curve, we may have and is complementary to the Bayesian process of calibration itself. We provide only a brief intuitive overview of the statistical method here, but see Heaton et al. (2020a in this issue) for more detail.

Our splines are special smooth piecewise-cubic curves connected together at what are called "knots". These knots lie at specific calendar ages generally selected by the user in advance. Between any pair of adjacent knots, the curve is a separate cubic but constructed in such a 
way to ensure that, at the knot marking the join with the next section, the cubic pieces not only link up continuously but the overall spline remains smooth. The more knots in a section, the more the overall spline can vary in that time period (wiggliness).

When fitting a Bayesian spline, we aim to find an overall curve that goes close to the observed data, taking into account their uncertainties, but which is not so overly wiggly as to overfit the data and introduce features that are not truly present. Further, we can adapt curve wiggliness to the data and our calibration needs by making an appropriate choice of the underlying knots that we place at specific calendar ages. Choice of placing and number of knots is often application specific, based on judgment concerning the underlying smoothness of the curve and the data density, as well as computational efficiency. The more knots that we have in a particular calendar range, the more detail we can provide in the calibration curve. In time periods where our underlying data is dense and we wish to identify precise detail in the curve, down even to an annual level, we place our knots similarly densely. In particular, we can incorporate Miyake-type events by packing knots around their known times. Conversely, where our underlying data is sparse and it is not possible to resolve fine-scale details, we place our knots more sparsely. For the predominantly dendrodated portion of the curve, extending from approximately 0-14 cal kBP, IntCal20 places over 2000 knots. Such a selection enables close to annual resolution in the detail of the final curve for the Holocene while still maintaining computational feasibility in curve construction.

The new curve construction approach also contains developments in its incorporation of uncertainty. Despite, as described above, the best attempts to quantify all ${ }^{14} \mathrm{C}$ uncertainty there are still some sources of variation which are difficult for a laboratory to capture. Potential examples include the variation between local region, genera/species, or growing season. This would manifest itself in ${ }^{14} \mathrm{C}$ observations from the same calendar year that are more widely spread (i.e. over-dispersed) than would be expected given their initial, laboratory quoted, error. In order to take account of such potential factors, and hopefully ensure we do not provide an overly precise calibration curve, we assess the level of overdispersion in the IntCal20 data during curve construction. This over-dispersion gives us a measure of additional variation seen in ${ }^{14} \mathrm{C}$ determinations when compared to a single hemispheric curve. We propagate this additional variation through to the final curve in the form of predictive intervals on the basis that it is equally likely to be present in uncalibrated data. However, users should be aware that our estimate of over-dispersion in ${ }^{14} \mathrm{C}$ observations is based upon tree-ring determinations only. Caution should be applied when calibrating other material where further potential sources of additional variation exist.

For the majority of calibration users, their use of the published IntCal20 will remain as for IntCal13. However, a few general elements are worthy of further description:

\section{Curve Realizations}

Being Bayesian, the construction methodology provides not just a single potential ${ }^{14} \mathrm{C}$ history but rather a large set of possible histories, each of which we call a realization. The published IntCal20 curve is a summary of all of these individual plausible histories-the posterior mean and variance of a large collection of realizations at each calendar age independently. These curve summaries provide the correct calibrated age for a single individual determination in a fast and efficient manner. 
However, the realizations give further information on curve covariance that is lost in the pointwise IntCal20 summary. When calibrating multiple ${ }^{14} \mathrm{C}$ determinations jointly, for example in wiggle matches or to test the duration of an event, this covariance has the potential to be used (see, for example, Blackwell and Buck 2008). Moving forward, the IntCal group is looking at the best way to provide and incorporate this covariance information into calibration for such users seeking ultimate precision in calibrating multiple dates jointly.

\section{Increased Likelihood of Multimodal Calendar Ages}

The increase in the annual detail afforded by IntCal20 is likely to lead to a greater chance that a calibrated age will have a multimodal posterior where annual fluctuations in ${ }^{14} \mathrm{C}$ levels lead to two or more possible fits to the curve. This is particularly likely when the curve shows plateaus. Such an occurrence can be seen in our example discussing calibration of the ${ }^{14} \mathrm{C}$ determinations relating to the Minoan Santorini (Thera) eruption. Multimodality requires care to be taken when reporting the calibrated age so as not to report calendar ages when there is little chance of the object arising e.g. the posterior mean may equate to a trough between the posterior modes. We therefore recommend the use of highest posterior density (HPD) regions when reporting posterior age intervals which will split the calibrated age range into disjoint intervals if needed. Multimodality may also increase complexity in practical interpretation if an object has two or more significantly different calendar dates. To reduce the likelihood of multimodal posteriors, we recommend the use of wiggle matching/joint modeling of multiple dates if possible.

\section{Posterior Calibrated Ages of IntCal20 Data}

An additional benefit of the Bayesian approach of IntCal20 is that each datum within the calibration database for which the calendar age is uncertain is itself calibrated during curve construction. We are able to provide posterior calibrated ages for all such records, for example, Lake Suigetsu, the various marine datasets, and the speleothem records.

\section{INTCAL20: ILLUSTRATION OF NEW CURVE ASPECTS}

\section{The Younger Dryas and Glacial/Holocene Transition}

Over the years, every IntCal update showed progress on dendrochronology and ${ }^{14} \mathrm{C}$ dating for the Glacial/Holocene boundary (e.g. Kromer et al. 2004; Kaiser et al. 2012). This effort has required both absolute tree-ring dates and wiggle matching of floating chronologies. Since IntCal13, significant contributions have been made by Hogg et al. (2016), Capano et al. (2017), and Reinig et al. (2020 in this issue).

The dendrochronological part of the present calibration curve IntCal20 now extends back to 13,910 calBP, well into the Bølling/Allerød (B/A) climatic zone. Relatively small but significant changes in the curve are made during the end of the B/A and the onset of the Younger Dryas (YD) cold phase. Compared with IntCal13, the IntCal20 calibration curve is slightly shifted, generally by about 50 calBP, in the older (calendar years) direction, i.e. a ${ }^{14} \mathrm{C}$ determination calibrated against IntCal20 will be given an older calendar age estimate than if it had been calibrated against IntCal13. The dramatic onset of the YD is characterized by a steep slope in the calibration curve, corresponding to an increase of about $5 \%$ in the atmospheric ${ }^{14} \mathrm{C}$ content $\left(\Delta^{14} \mathrm{C} \approx 50 \%\right)$ and which signifies the shutdown of the "ocean conveyor" (Broecker 1997). 


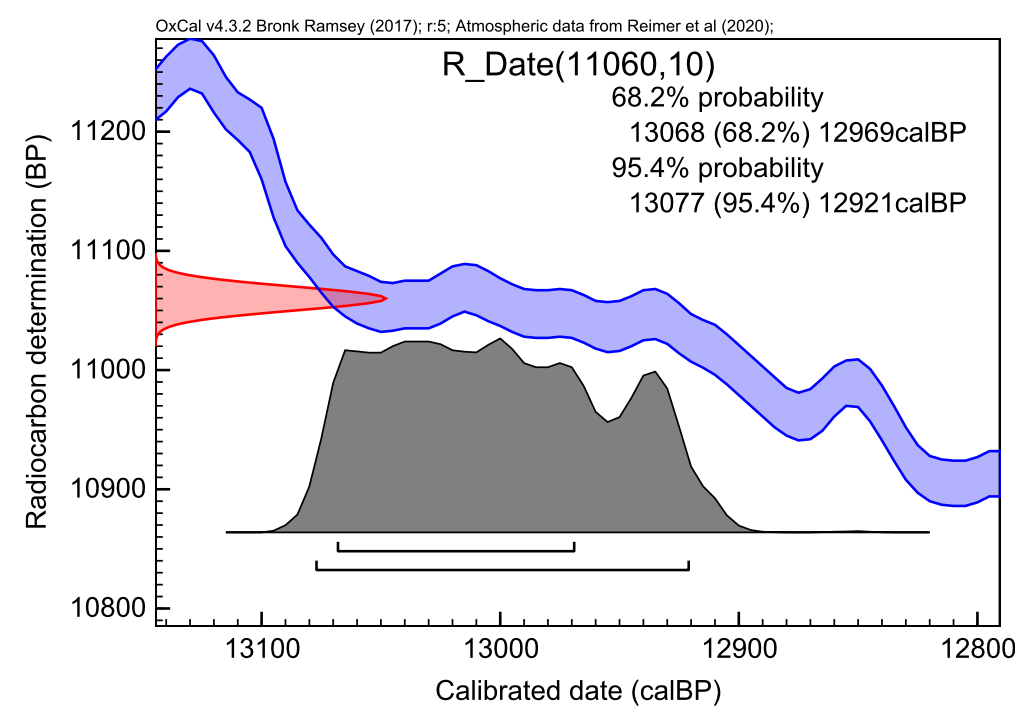

Figure 1 Calibrating the Laacher See tephra horizon.

During the Pleistocene/Holocene transition period, strong climatic variations took place, as well as megafauna extinctions. For a review and references, we refer to Fiedel (2011). The shift in IntCal20 now moves absolute calendar dates older by about 50 years and in the direction of the Holocene boundary as observed in Greenland ice, dated at 11,653 \pm 99 cal BP (maximum counting error (MCE), equivalent to 2- $\sigma$, Rasmussen et al. 2014). Note that the dates in Table 1 in the latter publication are given in $b 2 k$, i.e. calendar ages relative to $2000 \mathrm{AD}$; this has been taken into account.

An important time anchor for the last glacial boundary is the Laacher See eruption in Germany. The ${ }^{14} \mathrm{C}$ date for this eruption has been established as $11,060 \pm 10 \mathrm{BP}(1-\sigma$, Kromer et al. 2004). This corresponds to a calibrated range of $12,850-13,050$ calBP (95.4\% confidence or $2-\sigma$ ) using IntCal13. Note that, due to the plateau in the calibration curve that exists at the start of the $\mathrm{YD}$, the high precision seen in the ${ }^{14} \mathrm{C}{ }^{14} \mathrm{C}$ date (in $\mathrm{BP}$ ) is not converted into a precise calendar age estimate. However, we can say that using IntCal20 will move this anchor date more into the $\mathrm{B} / \mathrm{A}$, and away from the YD boundary with a calibrated range of $12,920-13,080$ calBP $(95.4 \%$ confidence or $2-\sigma$, see Figure 1$)$. The ${ }^{14} \mathrm{C}$ date is calibrated using OxCal v.4.3.2 (Bronk Ramsey 2009b) using the new IntCal20 calibration curve. We have rounded the calibrated result to 10 calBP.

\section{The Minoan Santorini (Thera) Eruption}

For calibration purposes, chronological anchor points provide crucial tests. A case in point of major importance is the catastrophic Minoan eruption of the Santorini/Thera volcano in the second millennium BC, a crucial anchor for Bronze Age prehistory. The precise date of the eruption has been debated for decades. Using a Greenland ice core chronology, the Thera eruption was originally thought to date to around $1645 \mathrm{BC}$ based upon volcanic tephra found in the core. However, a recent and timely analysis shows that these volcanic horizons are more likely to be the result of eruptions in Alaska rather than Thera (McAneney and Baillie 2019). ${ }^{14} \mathrm{C}$ dating obviously plays a major role in this discussion. The debate has 
been and still is that ${ }^{14} \mathrm{C}$ shows older dates than archaeological dating of the eruption, up to more than a century. For a recent overview of this debate, see Antiquity (2014).

Summarized, the ${ }^{14} \mathrm{C}$ date of the eruption can be taken as $3350 \pm 10 \mathrm{BP}(1-\sigma)$, which is an average of many dates from key sites like Palaikastro and Akrotiri (Bronk Ramsey et al. 2004; Bruins et al. 2008). This number (the ${ }^{14} \mathrm{C}$ date) is confirmed by other analyses (Höflmayer 2012) and consistent with other records like tsunami deposits on Crete (Bruins et al. 2008). Calibrating this ${ }^{14} \mathrm{C}$ date with calibration curves prior to the present IntCal20 curve yields a calendar date of the event in the late 17 th century BC, most notably by wiggle matched ${ }^{14} \mathrm{C}$ dates of tree rings from an olive tree killed by the eruption. This resulted in a date of 1627-1600 BC for the event (Friedrich et al. 2006), between 100-150 years older than previous traditional archaeological assessments.

This difference between archaeology and ${ }^{14} \mathrm{C}$ has spawned debates lasting decades (Kutschera et al. 2012; Antiquity 2014; Manning 2014; Bruins and van der Plicht 2017). Thus far, the debate has been largely focused on possible errors on either side, ${ }^{14} \mathrm{C}$, or archaeology. However, there is also the option that both are correct (or at least not very wrong), rather that there is a problem with the connection between the two: that is the calibration, which translates BP dates into calendar ages.

Very recently, new insights on the matter have been revealed. First, the validity of olive trees for wiggle match dating was questioned (Ehrlich et al. 2018). This is not further discussed here. Second, a new single year calibration curve for the Minoan Santorini time range became available, showing the possibility of an early 16th century BC date for the eruption (Pearson et al. 2018). Note that a small wiggle in the calibration curve around 1570 BC (3520 calBP) is just missed by previously released curves. If a ${ }^{14} \mathrm{C}$ age happens to coincide with this wiggle then it opens up an additional potential calendar age fit at this time and hence increases the probability of a younger (more recent) calendar date for the eruption.

This development led to major ${ }^{14} \mathrm{C}$ (re)dating efforts of wood dated by dendrochronology for the relevant time range. Several laboratories measured single year rings with ultimate precision during the construction time of IntCal20. The datasets are reported in this issue (Friedrich et al. 2020; Kuitems et al. 2020). As a result, the "Thera time-range" presently has the best-dated calibration curve, with over 800 high-precision measurements on dendrochronologically dated wood between 1700 and 1500 calBC, obtained by several independent AMS laboratories.

The result is that indeed between ca. 3600 and 3500 calBP the calibration curve needs a shift of about 20 BP upwards in ${ }^{14} \mathrm{C}$ age, as can be seen in Figure 2. By itself, this confirms the original observation by Pearson et al. (2018) and so, after calibration, the calendar dates will, therefore, become younger by a certain amount. What does this mean in practice for the calendar date of the Minoan Santorini/Thera eruption? We will illustrate this as follows:

First, we calibrate the well-published averaged date $3350 \pm 10$ BP $(1-\sigma)$ using both curves; see Figure 3. Note that the calibrated dates are shown here in BC.

This example highlights that near plateaus in the calibration curve, or during periods of significant wiggles, it is highly likely that calibrated age estimates arising from single ${ }^{14} \mathrm{C}$ determinations will exhibit significant multimodality. In the presence of such multimodality, practical interpretation of dating is more complex and it is critical that 


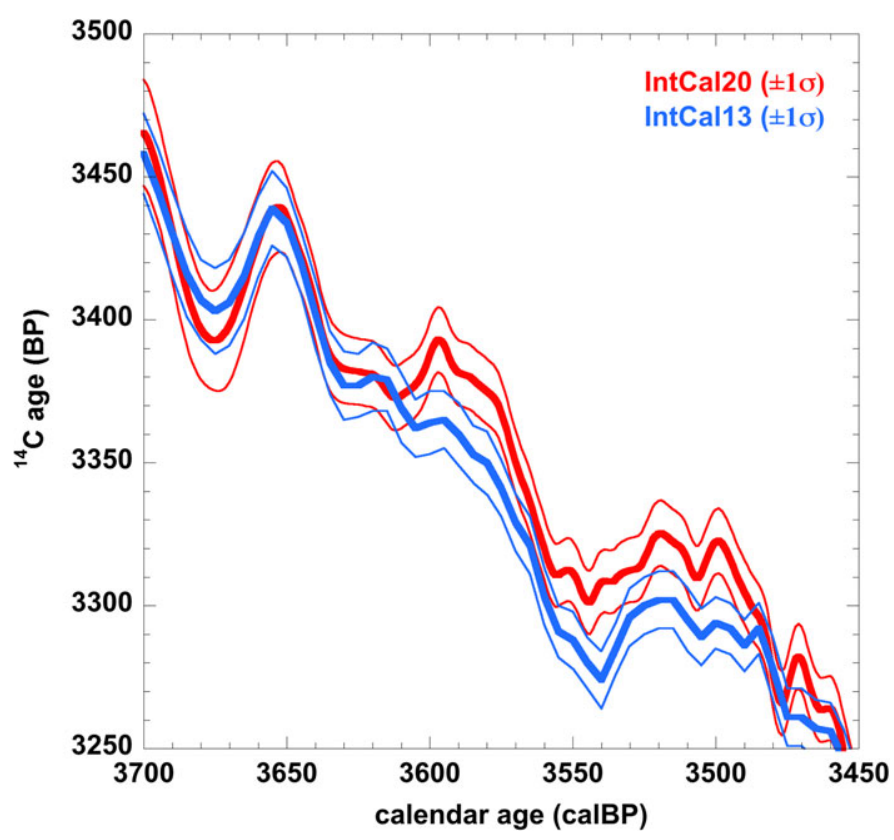

Figure 2 The IntCal20 (red) and IntCal13 (blue) calibration curves for the time range relevant to the Thera eruption. The thick lines represent the posterior mean of each curve; the thin lines represent the 1- $\sigma$ credible/ predictive interval. (Please see electronic version for color figures.)

care is taken to provide such interpretation correctly. Reporting single $68.2 \%(1-\sigma)$, or $95.4 \%(2-\sigma)$, intervals will typically be inappropriate and we instead recommend considering HPD regions.

With IntCal13, the posterior calendar age estimate is approximately unimodal (i.e. shows a single large peak). In such an instance, it is reasonable to report a single interval-here we obtain a $68.2 \%(1-\sigma)$ interval extending from $1658-1624$ calBC; and a $95.4 \%(2-\sigma)$ interval of $1683-1617$ calBC.

However, with IntCal20 the picture is much more complex as our ${ }^{14} \mathrm{C}$ date of $3350 \pm 10 \mathrm{BP}$ hits the plateau in the curve. There are now multiple, disjoint, calendar age ranges consistent with this ${ }^{14} \mathrm{C}$ date. A single interval is not therefore sufficient to summarize these possibilities. Instead, we see that there are perhaps five separate calendar age regions each with significant probabilities attached. In providing interpretation, we would suggest reporting all these regions with their associated probabilities.

If, for IntCal20, we want to provide the equivalent of a 2- $\sigma$ interval (i.e. the smallest set of calendar ages which contains the true age with a probability of $95.4 \%$ ), then should report the HPD region. This consists of all the intervals quoted in the 95.4\% OxCal summary i.e. 1733-1719, 1688-1651, 1645-1608, 1604-1602, 1583-1559, and 1556-1544 calBC. The individual probabilities for these ranges are $3.5,22.1,53.0,0.3,11.4$, and $5 \%$ respectively. The latter two, representing calendar dates in the 16th century BC, have a combined probability of $16.4 \%$. A more recent date is, therefore, a distinct possibility, although we note that the peak centered around 1625 calBC carries the largest individual probability. We also note that a further small peak at an older age of ca. 1665 calBC appears, introduced by the refined revision, and increased wiggliness, of the new curve. 

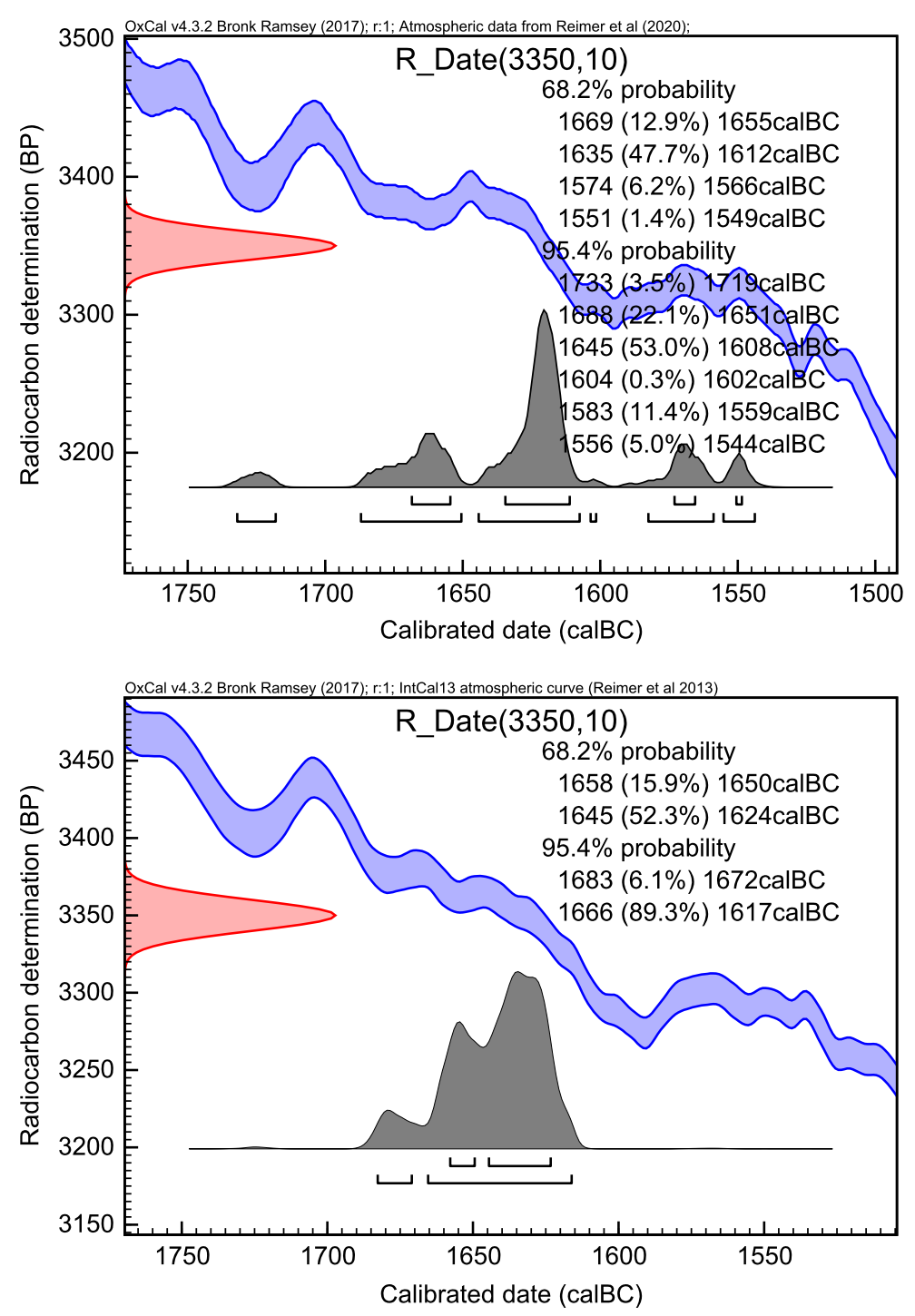

Figure 3 Calibration of the averaged Thera date $3350 \pm 10 \mathrm{BP}$, using IntCal20 (top) and IntCal13 (bottom).

We further calculated the probability of a calendar date more recent than 1600 calBC (equivalently 3550 calBP) by summing the individual posterior probabilities of all calendar ages in that period. This provided an estimated probability of $19.3 \%$ for a calendar date in the 16 th century $\mathrm{BC}$.

Second, we reanalyze the wiggle match date of the olive branch published by Friedrich et al. (2006). In the original publication, the actual calibration curve at the time was IntCal04. Subsequent calibration curves (IntCa109, IntCal13) did not significantly change the results. What will change using IntCal20? 


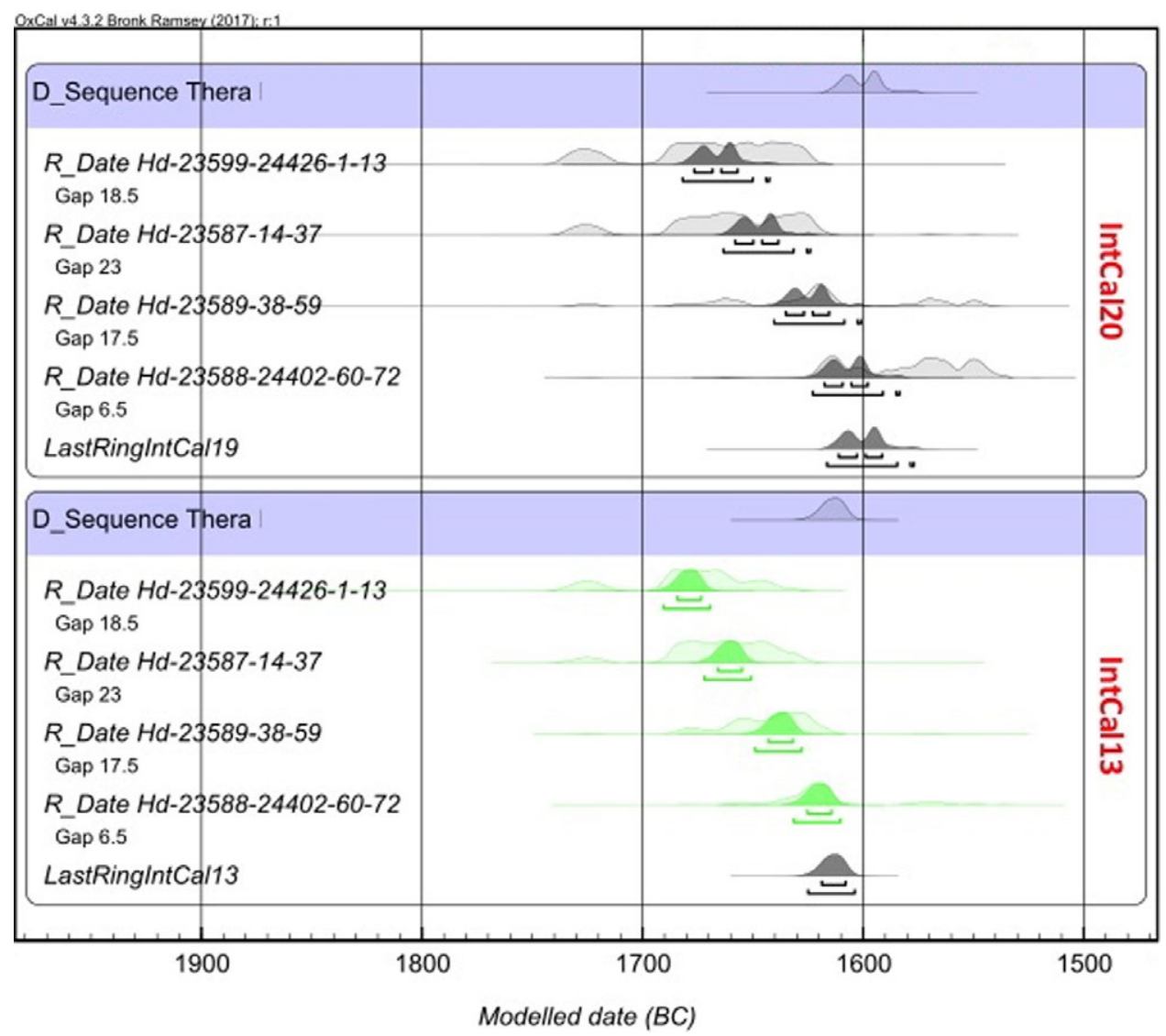

Figure 4 Dating the Minoan Thera eruption (Friedrich et al. 2006) by wiggle matching rings from an olive tree branch, using the calibration curves IntCal20 (top) and IntCal13 (bottom).

The results of wiggle matching the olive tree dates are shown in Figure 4. For completeness we give here the four ${ }^{14} \mathrm{C}$ dates of Friedrich et al. (2006), measured by radiometry in Heidelberg: rings $1-13,3383 \pm 11 \mathrm{BP}$; rings $14-37,3372 \pm 12 \mathrm{BP}$; rings $38-59,3349 \pm 12 \mathrm{BP}$; rings $60-72$, $3331 \pm 10 \mathrm{BP}($ all at $1-\sigma)$.

For IntCa120, we see that through wiggle matching, multimodality in the calendar age estimate is reduced. This is typically to be expected since, when wiggle matching, we can use the shape of the curve in addition to its absolute value. The resulting calendar dates for the last ring are 1612-1592 calBC (68.2\% confidence) and 1617-1578 calBC (95.4\% confidence). For IntCal13, this is $1619-1608$ calBC $(68.2 \%$ confidence) and 1625-1604 calBC (95.4\% confidence).

However, even here, we need to be somewhat careful with our interpretation as the IntCal20 estimate still retains two distinct peaks suggesting the two most likely periods for the last ring are either ca. 1605 calBC (3555 calBP) or ca. 1595 calBC (3545 calBP). Both these IntCal20based potential calendar dates are more recent than the calendar age estimate obtained using IntCal13 (or earlier curves) by about 5-15 years showing the effect of the calibration curve change assuming the validity of the olive wood wiggle match. 
Summarizing, for the Minoan Santorini/Thera eruption, we have with IntCal20 a relatively small revision to the curve itself which nonetheless has a significant impact not only in the calibrated ages it provides but also in how those age estimates may need to be reported and interpreted. Until IntCal20, the calibration curve in this time range was based on relatively sparse data (conventional dates measured decades ago, with relatively large temporal resolution). Now we have obtained by way of an unprecedented effort a firm establishment of the calibration curve during one of the most important prehistoric chronological anchorpoints.

However, in terms of establishing the exact date of Thera, the new calibration curve interestingly still leaves questions unanswered due to the presence of the plateau in IntCal20 during the contested time period. To gain more precise insight into the timing using ${ }^{14} \mathrm{C}$, modeling of multiple ${ }^{14} \mathrm{C}$ dates will likely be needed. The ${ }^{14} \mathrm{C}$ dates are calibrated using OxCal v.4.3.2 (Bronk Ramsey 2009b) with a 1-year resolution.

\section{The Middle and Upper Paleolithic Period}

Chronological studies suggest that Neanderthals disappeared approximately between 39 and $41 \mathrm{ka}$ ago, which implies that they overlapped with Archaic Homo Sapiens for at least 2600 years and up to 5400 years (Higham et al. 2014). Additional evidence for the co-existence of these two human species is represented by DNA data obtained from the analysis of an Archaic Homo Sapiens (37-42 ka calBP) from Romania, showing that between 6 and 9\% of the genomic sequence of this individual was derived from Neanderthals (Fu et al. 2015).

Despite the present state of the research, there remains still much to understand on the chronology of the Middle-to-Upper Paleolithic transition, i.e. on the period during which Archaic Homo Sapiens replaced Neanderthals in Eurasia, in order to construct a fairly convincing outline sketch of human prehistory and of the context in which it played out. Here, very precise and accurate calibration of ${ }^{14} \mathrm{C}$ ages, back to ca. 50,000 years ago, is critical to limit archaeological speculations, developing solid chronologies of paleoenvironmental change and a more detailed understanding of the succession of climatic events through the last glacial period. In this paper, we will show what implications the new IntCal20 has for the understanding of the relationship between these two fascinating species using some of the most striking direct dates of human fossils in Eurasia. All the ${ }^{14} \mathrm{C}$ dates are calibrated using OxCal v.4.3.2 (Bronk Ramsey 2009b), and using both IntCal13 and the new IntCal20 calibration curve (Figure 5). The Figure 5 also shows part of the Greenland ice chronology (Rasmussen et al. 2014). There are scale differences, but at this time range, the offsets are not significant beyond the 1- $\sigma$ level. See Adolphi et al. (2018) and also Muscheler et al. (2020 in this issue). All the results are rounded by 10 years.

\section{Oase 1 and Ust-Ishim}

A Homo sapiens mandible (Oase 1) found in Romania (Peştera cu Oase) has been directly dated in the Oxford and Groningen laboratories yielding a mean age of 34,950 $\pm 990 \mathrm{BP}(1-\sigma$, Trinkaus et al. 2003). The IntCal13 calibration places the Oase 1 individual at 40,670 38,520 calBP at $68.2 \%$ confidence, and at $41,770-37,310$ calBP at $95.4 \%$ confidence.

This calibration provides evidence for an early Homo sapiens in Europe. Moreover, the genetic study found out that the Neanderthal-like DNA shares more alleles (between 6-9\%) with the Oase 1 individual than it does with any present-day humans in Eurasia. They also estimated how far in time this introgression happened. They concluded that the Neanderthal contribution 


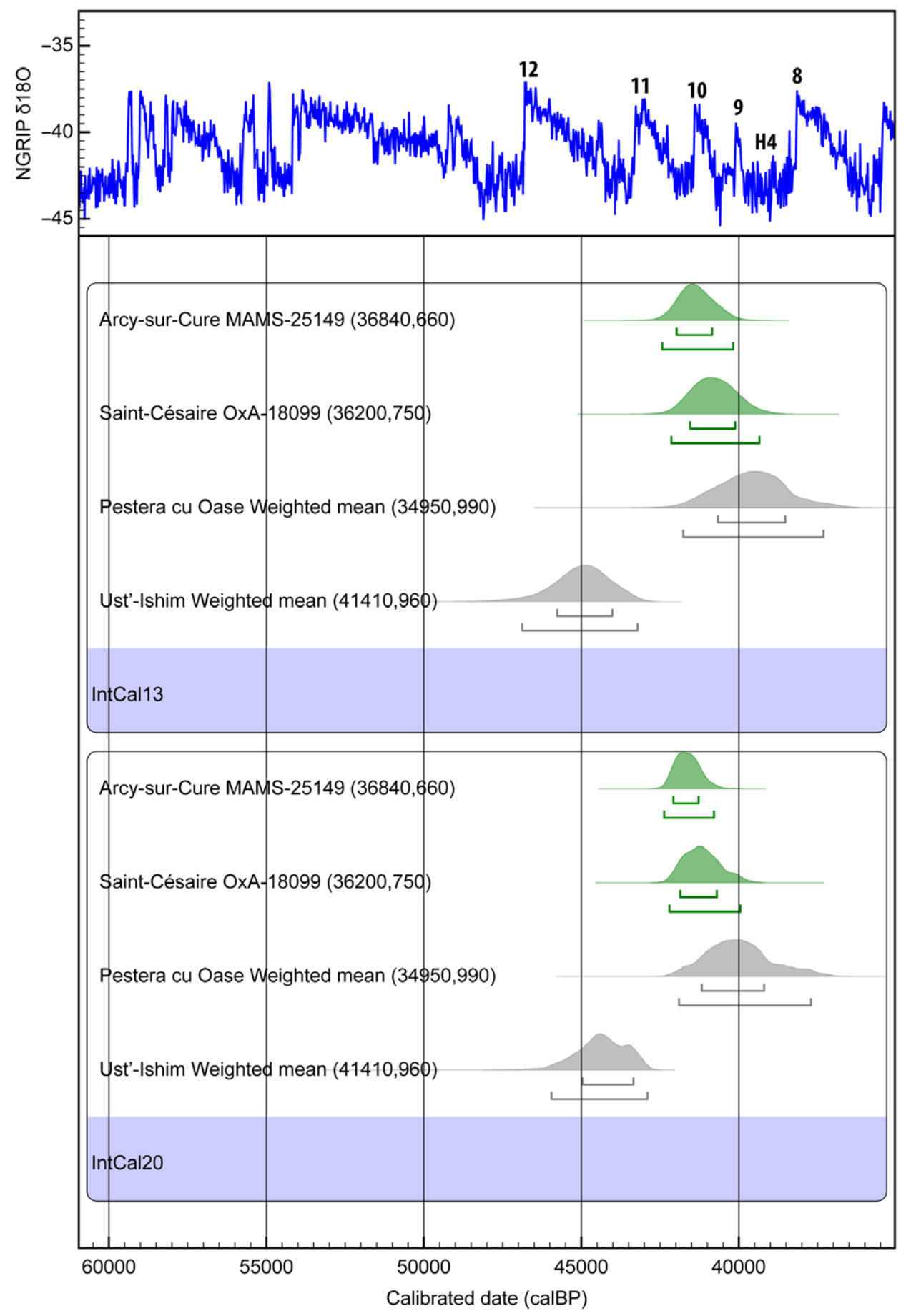

Figure 5 The calibrated ${ }^{14} \mathrm{C}$ ages using IntCal13 of Oase 1 and Ust'-Ishim are shown in grey, and Arcysur-Cure and Saint Césaire in green on top. The corresponding calendar age intervals using IntCal20 are shown at the bottom. The results are linked with the (NGRIP) $\delta^{18} \mathrm{O}$ climate record. The numbers from 12 to 8 represent the warm Dansgaard-Oeschger (DO events 12 to 8), and one cold Heinrich Event (H4). 
to the Oase 1 individual occurred recently in his family tree, four to six generations back, which means the Neanderthal admixture is dated less than 200 years before the time Oase 1 lived (Fu et al. 2015).

The recalibration with IntCal20 provides a new time span for this important human fossil, placing his calendar age back in time, between $41,180-39,190$ calBP at $68.2 \%$ confidence, and at 41,900-37,700 calBP at 95.4\% confidence (see Figure 5). This shift to older ages of the presence of Homo sapiens at the site implies a longer overlap with Neanderthals in this region.

Another directly dated key human fossil was found in Siberia (Ust'-Ishim). In this case, it is the oldest Homo sapiens so far found in Eurasia (Fu et al. 2014). This individual carries a similar amount of Neanderthal DNA ancestry as present-day Eurasians. In this case, the Neanderthals gene flow occurred 7000 to 13,000 years before Ust'-Ishim lived. Here two dates were made in Oxford using the ultrafiltration method: OxA-25516 with a ${ }^{14} \mathrm{C}$ Age of 41,400 $\pm 1300 \mathrm{BP}(1-\sigma)$ and the second OxA-30190 with a ${ }^{14} \mathrm{C}$ Age of 41,400 $\pm 1400 \mathrm{BP}(1-\sigma)$. Applying R_Combine in OxCal we obtain an age of 41,400 $\pm 953(1-\sigma)$. Calibrating against IntCal13, this corresponds to a calendar age of $45,770-44,010$ calBP at $68.2 \%$ and $46,880-43,210$ calBP at $95.4 \%$ (see Figure 5). With this result, the authors concluded that: interestingly the Ust'-Ishim individual probably lived during a warm Dansgaard-Oeschger period (DO 12) (Fu et al. 2014), which has been proposed to be a time of expansion of Homo sapiens into Europe (Müller et al. 2011; Hublin 2012).

With the new calibration curve IntCal20, these ranges changes to 44,970-43,340 calBP at $68.2 \%$ and $45,950-42,890$ calBP at $95.4 \%$. This shift to younger ages puts the Ust'-Ishim individual closer or even into the stadial following DO 12 (see Figure 5).

\section{The Châtelperronian}

Another two, directly dated, important hominins are Neanderthals from France. The first is the Neanderthal fossil of Saint Césaire (La Roche-à-Pierrot) situated in the Charente-Maritime department of southwestern France (Lévêque and Vandermeersch 1980). The second one comes from Grotte du Renne (Arcy-sur-Cure) located on the main road between Auxerre and Avallon, close to Paris (David et al. 2001). Both of them are crucial to understanding the replacement processes of Neanderthals by Homo sapiens and the interpretation of socalled "transitional industries", here the Châtelperronian.

The question of whether Neanderthals manufactured the Châtelperronian is the topic of intense debate since the Châtelperronian industry represents a new cultural behavior. The debated question is if the Châtelperronian new behavior demonstrates a cultural influence, on the last Neanderthals, by contemporaneous Archaic Homo Sapiens populations, already present further east in Europe, or if it represents a Neanderthal invention. Here, direct ${ }^{14} \mathrm{C}$ dates of hominins together with a precise calibration curve play a pivotal role.

The Saint Césaire bone was pretreated at the Max Planck Institue, Leipzig, Germany, and graphitized and dated in Oxford to a ${ }^{14} \mathrm{C}$ age of 36,200 \pm 750 (OxA-18099, 1- $\sigma$ ) (Hublin et al. 2012). The Arcy-sur-Cure bone was pretreated at the Max Planck and graphitized and dated in Mannheim, Germany to a ${ }^{14} \mathrm{C}$ age 36,840 \pm 660 (MAMS-25149, 1- $\sigma$ ) (Welker et al. 2016). The respective calibrated ages using IntCal13 are 41,550-40,110 calBP at $68.2 \%$ and $42,150-39,340$ calBP at $95.4 \%$ for Saint Césaire, and 41,980-40,840 calBP at $68.2 \%$ and $42,430-40,180$ calBP at $95.4 \%$ for Arcy-sur-Cure (Figure 5). 
IntCal20 provides a new calibration for Saint Césaire between 41,860-40,690 calBP at $68.2 \%$ and $42,200-39,940$ calBP at $95.4 \%$. For Arcy-sur-Cure the ranges are between $42,080-41,270$ calBP at $68.2 \%$ and $42,370-40,780$ calBP (Figure 5).

\section{Conclusion}

These examples demonstrate that for some intervals, here 40 ka calBP vs. $45 \mathrm{ka}$ calBP, the new calibration curve will result in narrower ranges for calibrated ages i.e. more precise dating than the previous IntCal13. The more detailed IntCal20 calibration curve will, therefore, allow higher precision for the study of human evolution in terms of chronological overlap between archaeological sites and different human species and will provide better resolution in relation to climatic events.

\section{Regional and Seasonal Effects}

A full discussion of possible regional effects with associated references is given in the main IntCal20 paper (Reimer et al. 2020 in this issue). The conclusion drawn there is that there is as yet insufficient information to quantify such effects or indeed to fully understand the contribution from different underlying mechanisms. The potential issues are: different growing seasons for the material dated compared to the calibration datasets, localized addition of $\mathrm{CO}_{2}$ from different reservoirs (such as ocean upwelling, anthropogenic sources, and local volcanic vents), mixture of air masses from both hemispheres in the tropics (Hogg et al. 2020 in this issue), and overall trends with latitude or altitude. Some of these effects are potentially related because the known subannual cycle in ${ }^{14} \mathrm{C}$ (Appenzeller et al. 1996; Stohl et al. 2003) will necessarily lead to differences in the ${ }^{14} \mathrm{C}$ signal seen in different species and different latitudes. Furthermore, even the same species may grow differently due to circumstances such as water availability and other localized stresses. Fortunately, with the exception of the major addition of carbon from other reservoirs, most seasonal or regional effects are likely to be less than $20{ }^{14} \mathrm{C}$ years or $2.5 \%$ and so comparable to the measurement precision.

In considering the practical consequences of such regional and seasonal effects, statistically, we can treat measurements which are systematically offset irrespective of the underlying cause. This is particularly important where complex Bayesian models or wiggle-matching of tree ring data is being undertaken to achieve precisions approaching the decadal level. In these cases, it is prudent to build into the model the possibility that all of the ${ }^{14} \mathrm{C}$ dates might be systematically offset by some small amount, whether this is due to an offset resulting from the measurement methodology, or within the sample itself relative to the hemispherical average atmosphere. Particularly in the case of wiggle-matched tree ring data, the measurement series itself will often provide sufficient evidence for whether there is such an offset. In general, it is better to provide a prior which reflects our expectation that such offsets will be small (for example, $\mathrm{N}\left(\mu, \sigma^{2}\right) \sim \mathrm{N}\left(0,10^{2}\right)$ ). This can be achieved, for example, in OxCal (Bronk Ramsey 2009a) by using the Delta_R methodology normally applied to marine samples (as was used as a sensitivity test in Bronk Ramsey et al. 2010). The code for this is:

\footnotetext{
Delta_R(“offset”,0,10);

or

Delta_R(“offset”, N(0,10));
} 
Such an approach can also be used for single calibrations by adding in additional error in quadrature to reflect such uncertainty. However, before doing this, one should know whether this uncertainty has already been included within the error quoted by the laboratory. The overall effect on large datasets is likely to be much more significant in that any offsets are potentially correlated across the dataset as a whole, something which the lab cannot quantify (unless it is purely a measurement issue). It is important to remember that there is ultimately an irreducible uncertainty in our chronologies, irrespective of the number of measurements we make.

If one wishes to use the data to determine such an offset with no bias, a uniform prior (for example $\sim \mathrm{U}(-20,20))$ for the offset can be used, and the marginal posterior for the offset determined as part of the analysis. The OxCal code for this would be:

\section{Delta_R(“offset”,U(-20,20));}

The treatment of samples that come from close to the ITCZ is slightly different. Here we know the direction of the offset which we expect to see from whichever hemisphere we think is dominant. In such cases, it would be possible to use a mixed reservoir model, where we assume that the ${ }^{14} \mathrm{C}$ could be drawn from a mixture of the northern and southern hemisphere atmospheric reservoirs. An alternative is to use the same approach as above but with a biased offset. In practice, for example, using the Northern Hemisphere curve with an offset of $\sim \mathrm{U}(0,40)$ will give a similar result to using the Southern Hemisphere curve with an offset of $\sim \mathrm{U}(-40,0)$. The difficulty in doing this is putting a more constrained prior on the expected mixture, which will be very location dependent; the above uniform distributions are very conservative but obviously add in significant extra uncertainty unless the dataset includes some samples of known age which will constrain the marginal posterior for the offset. Such situations are potentially very complex in that different samples, particularly if from different species, might pick up different signals even in the same location because of growing season changes in the ITCZ.

\section{The Marine Curve}

The slow diffusion of $\mathrm{CO}_{2}$ into and out of the surface ocean combined with the very slow circulation of the deep ocean results in a ${ }^{14} \mathrm{C}$ age offset or reservoir effect $(\mathrm{R}(\mathrm{t}))$ between samples that lived on land and those that lived at the same time in the ocean. The present day value of this offset is of the order of approximately $400{ }^{14} \mathrm{C} \mathrm{yr}$; however, $\mathrm{R}(\mathrm{t})$ varies regionally and is time dependent. For sample ${ }^{14} \mathrm{C}$ calibration of marine-based determinations, the regional variation has usually been handled by including a regional correction to the marine calibration curve called $\Delta \mathrm{R}$ but the time dependence of both $\mathrm{R}$ and $\Delta \mathrm{R}$ has made marine calibration more uncertain than for terrestrial samples.

The Marine20 curve (Heaton et al. 2020b in this issue) includes a global R(t) correction based on the BICYCLE box model (Köhler and Fischer 2004, 2006; Köhler et al. 2005, 2006) forced by our IntCal20 estimate of atmospheric ${ }^{14} \mathrm{C}$ along with several other paleoclimate records. While more complex ocean general circulation models (OGCMs) are available (e.g. Butzin et al. 2017, 2020 in this issue) which also provide spatial estimates for the marine ${ }^{14} \mathrm{C}$ reservoir, most archaeological marine samples derive from near coastal environments which are not well characterized by the grid size of such OGCMs. Consequently, the use of $\Delta \mathrm{R}$ with Marine20 can still be advised for these samples. Pre-bomb $\Delta \mathrm{R}$ values have been recalculated with Marine20 and are available at www.calib.org/marine20. Researchers 
calibrating marine ${ }^{14} \mathrm{C}$ ages from the open ocean sites may want to access the LSG OGCM model results (Butzin et al. 2020 in this issue) within the grid closest to the sample site available at https://doi.pangaea.de/. This is not discussed further here, for more details we refer to Heaton et al. (2020b in this issue).

\section{NOTE ON TIMESCALES}

For completeness, we summarize here the units and definitions for timescales that are relevant for ${ }^{14} \mathrm{C}$ dating.

\section{$B P$}

Defined unit for the ${ }^{14} \mathrm{C}$ timescale. Measured activities are to be reported following a convention. The definition concerns the usage of the halflife value, fractionation correction, and standard activity. For details, we refer to the literature (Stuiver and Polach 1977; Mook and van der Plicht 1999).

$A D$

Anno Domini, calendar date as commonly used in western society.

$\mathrm{AD}$ is the same as CE (Common Era) which is mostly used in Near Eastern contexts.

calAD

Calendar date, obtained after calibration of a ${ }^{14} \mathrm{C}$ date (expressed in BP).

$B C$

Calendar date before (the birth of) Christ, which is traditionally placed in $1 \mathrm{AD}$. BC is the same as BCE (Before Common Era).

The year " 0 " does not exist in the traditional calendar; the year $1 \mathrm{BC}$ precedes $1 \mathrm{AD}$.

calBC

Calendar date, obtained after calibration of a ${ }^{14} \mathrm{C}$ date (expressed in $\left.\mathrm{BP}\right)$.

calBP

Calibrated ${ }^{14} \mathrm{C}$ date, relative to the standard year $1950 \mathrm{AD}$.

Thus, calBP $=1950-$ calAD $=1949+$ calBC.

Note one exception to the above: modeled dates are given as BP. After applying Bayesian analysis of a series of ${ }^{14} \mathrm{C}$ dates only, this equals calBP. The latter is no longer the case when also dates resulting from other methods are included.

$b 2 k$

Calendar date relative to $2000 \mathrm{AD}$. This unit is not to be used for ${ }^{14} \mathrm{C}$ dating. We mention it here because it has recently been introduced by the ice core community to avoid confusion with "our" calBP (Rasmussen et al. 2014). The units BP and calBP are both used in e.g. Earth and Environmental sciences when dating methods other than ${ }^{14} \mathrm{C}$ are used. However, generally, they have a different meaning than the ${ }^{14} \mathrm{C}$ definitions given above. We should be aware that BP and calBP are not "owned" by the radiocarbon community.

\section{CONCLUSIONS}

The calibration curve to be used for calibration of ${ }^{14} \mathrm{C}$ dates has been updated. It is presently called IntCal20, to be used for terrestrial samples from the Northern Hemisphere. It replaces 
the previous curve IntCal13. Additional calibration curves associated with IntCal20 are Marine20 for samples from marine reservoirs, and SHCal20 for the Southern Hemisphere.

In this companion article, we have summarized the present status of calibration and discuss some highlights. The full background of curve construction is briefly summarized in order to provide users with an understanding of the method used. Details and reference to datasets are given in the main papers in this issue.

As before, the calibration curve can be considered as based on two kinds of records: dendrochronology and others. The tree ring part now extends to 13,910 calBP, well into the Late Glacial period. Here the main improvement since IntCall3 is the temporal resolution. For significant parts of (pre)history, single-year datasets have become available. This is spawned by the hunt for "Miyake events", sudden increases in the natural ${ }^{14} \mathrm{C}$ content of short duration, observed in tree rings. Equally important, the newest MICADAS AMS machines are very efficient, enabling the acquisition of an unprecedented amount of tree-ring dates with high resolution. This has revolutionized the field, including calibration.

A key illustration concerns the dating of the Minoan Santorini/Thera eruption. This is a crucial anchor point for prehistory in the 2 nd millennium BC. For decades, the absolute date of the eruption has been heavily debated by ${ }^{14} \mathrm{C}$ experts and traditional archaeological thinking. During the last few years, many high-resolution tree-ring measurements have been performed by various laboratories, which are now all integrated into IntCal20. The revised curve in the relevant time period is now annually resolved and shifted by a relatively small but crucial number of years (ca. $20 \mathrm{BP}$ ). As a consequence of this shift, there is a plateau in the calibration curve with detailed annual fluctuations that provide multiple potential fits with ${ }^{14} \mathrm{C}$ dates from the eruption. This has an impact not just in shifting calendar age estimates more recent, but also results in multimodal calendar age estimates that require significant care in interpretation. A much younger date-ca. $1500 \mathrm{BC}$, as advertised by some archaeologists-remains extremely unlikely, based on ${ }^{14} \mathrm{C}$.

For the Glacial part of the curve, beyond the tree ring record of 13,910 calBP, the main datasets originate from corals, speleothems, and the laminated sediment of Lake Suigetsu. The new IntCal20 integrated curve provides calibration back to 50,000 BP, which corresponds to 55,000 calBP. This part of the curve is applied to critical real-life chronological issues in Paleolithic archaeology. We discuss the absolute dates for the key Paleolithic sites Pestera $\mathrm{Cu}$ Oase (Romania), Ust'-Ishim (Siberia), Arcy-sur-Cure, and Saint Cesaire (France). We show that the more detailed IntCal20 calibration curve allows better precision for the study of human evolution in terms of chronological overlap between the presence of Homo sapiens and Neanderthals. It also provides better resolution in relation to climatic events.

\section{ACKNOWLEDGMENTS}

CBR is funded by NERC as part of their ${ }^{14} \mathrm{C}$ facility. TJH is funded by a Leverhulme Trust Fellowship RF-2019-14019, "Improving the Measurement of Time Using Radiocarbon". ST is funded by the European Research Council under the European Union's Horizon 2020 Research and Innovation Programme (grant agreement No. 803147-RESOLUTION). Discussions with M.W. Dee have been instrumental. 


\section{REFERENCES}

Adolphi F, Bronk Ramsey C, Erhardt T, Lawrence Edwards R, Cheng H, Turney CSM, Cooper A, Svensson A, Rasmussen SO, Fischer H, et al. 2018. Connecting the Greenland ice-core and $\mathrm{U} / \mathrm{Th}$ timescales via cosmogenic radionuclides: Testing the synchronicity of Dansgaard-Oeschger events. Climate of the Past 14:1755-1781.

Antiquity. 2014. Debate feature: Bronze Age catastrophe and modern controversy: dating the Santorini eruption. Antiquity 88:267-291.

Appenzeller C, Holton JR, Rosenlof KH. 1996. Seasonal variation of mass transport across the tropopause. Journal of Geophysical ResearchAtmospheres 101(D10):15071-15078.

Balter M. 2006. Radiocarbon dating's final frontier. Science 313:1560-1563.

Bayliss A. 2009. Rolling out revolution: using Radiocarbon dating in Archaeology. Radiocarbon 51:123-47.

Beck JW, Richards DA, Edwards RL, Silverman BW, Smart PL, Donahue DJ, Hererra-Osterheld S, Burr GS, Calsoyas L, Jull AJT, et al. 2001. Extremely large variations of atmospheric ${ }^{14} \mathrm{C}$ concentrations during the last glacial period. Science 292:2453-2458.

Blackwell PG, Buck CE. 2008. Estimating radiocarbon calibration curves. Bayesian Analysis 3:225-442.

Broecker WS. 1997. Thermohaline circulation, the Achilles heel of our climate system: will manmade $\mathrm{CO}_{2}$ upset the current balance? Science 278:1582-1588.

Bronk Ramsey C, Manning SW, Galimberti M. 2004. Dating the volcanic eruption at Thera. Radiocarbon 46:325-344.

Bronk Ramsey C, Buck CE, Manning SW, Reimer P, van der Plicht J. 2006. Developments in radiocarbon calibration for archaeology. Antiquity 80:783-798.

Bronk Ramsey C. 2009a. Dealing with outliers and offsets in radiocarbon dating. Radiocarbon 51: 1023-1045.

Bronk Ramsey C. 2009b. Bayesian analysis of radiocarbon dates. Radiocarbon 51:337-360.

Bronk Ramsey C, Dee MW, Rowland JM, Higham TFG, Harris SA, Brock F, Quiles A, Wild EM, Marcus ES, Shortland AJ. 2010. Radiocarbon-based chronology for Dynastic Egypt. Science 328:1554-1557.

Bronk Ramsey C, Staff RA, Bryant CL, Brock F, Kitagawa $\mathrm{H}$, van der Plicht J, Schlolaut G, Marshall MH, Brauer A, Lamb HF, et al. 2012. A complete terrestrial radiocarbon record for 11.2 to $52.8 \mathrm{kyr}$ BP. Science $338: 370-374$.

Bronk Ramsey C, Scott EM, van der Plicht J. 2013. Calibration for archaeological and environmental samples in the timerange 26-50 ka cal BP. Radiocarbon 55:2021-2027.

Bruins HJ, MacGillivray JA, Synolakis CE, Benjamini C, Keller J, Kisch HJ, Klugel A, van der Plicht J. 2008. Geoarchaeological tsunami deposits at Palaikastro (Crete) and the Late Minoan IA eruption of Santorini. Journal of Archaeological Science 35:191-212

Bruins HJ, van der Plicht J. 2017. The Minoan Santorini explosion and its ${ }^{14} \mathrm{C}$ position in archaeological strata: preliminary comparison between Ashkelon and Tell el-Dab'a. Radiocarbon 59:1295-1307.

Butzin M, Köhler P, Lohmann G. 2017. Marine radiocarbon reservoir age simulations for the past 50,000 years. Geophysical Research Letters 44:8473-8480.

Butzin M, Heaton TJ, Köhler P, Lohmann G. 2020. A short note on marine reservoir age simulations used in IntCal20. Radiocarbon 62. This issue.

Capano M, Miramont C, Guibal F, Kromer B, Tuna T, Fagault Y, Bard E. 2017. Wood ${ }^{14} \mathrm{C}$ dating with AixMICADAS: Methods and application to treering sequences from the Younger Dryas event in the southern French Alps. Radiocarbon 60:51-74.

Cheng H, Lawrence Edwards R, Southon J, Matsumoto K, Feinberg JM, Sinha A, Zhou W, Li H, Li X, Xu Y, et al. 2018. Atmospheric ${ }^{14} \mathrm{C} /{ }^{12} \mathrm{C}$ changes during the last glacial period from Hulu Cave. Science 362:1293-1297.

David F, Connet N, Girard M, Lhomme V, Miskovsky JC, Roblin-Jouve A. 2001. Le Châtelperronien de la grotte du Renne à Arcysur-Cure (Yonne). Données sédimentologiques et chronostratigraphiques. Bulletin de la Société Préhistoire Francaise 98:207-230.

Ehrlich Y, Regev L, Boaretto E. 2018. Radiocarbon analysis of modern olive wood raises doubts concerning a crucial piece of evidence in dating the Santorini eruption. Scientific Reports 8. doi: 10.1038/s41598-018-29392-9.

Fairbanks RG, Mortlock RA, Tzu-Chien C, Cao L, Kaplan A, Guilderson TP, Fairbanks TW, Bloom AL, Grootes PM, Nadeau MJ. 2005. Radiocarbon calibration curve spanning 0 to 50,000 years BP based on paired ${ }^{230} \mathrm{Th} /{ }^{234} \mathrm{U} /{ }^{238} \mathrm{U}$ and ${ }^{14} \mathrm{C}$ dates on pristine corals. Quaternary Science Reviews 24:1781-1796.

Fiedel S. 2011. The mysterious onset of the Younger Dryas. Quaternary International 242:262-266.

Friedrich WL, Kromer B, Friedrich M, Heinemeier J, Pfeiffer T, Talamo S. 2006. Santorini eruption dated to 1627-1600 BC. Science 312:548.

Friedrich R, Kromer B, Wacker L, Olsen J, Remmele S, Lindauer S, Land A, Pearson C. 2020. A new annual ${ }^{14} \mathrm{C}$ dataset for calibrating the Thera eruption. Radiocarbon 62. This issue.

Fu Q, Hajdinjak M, Moldovan OT, Constantin S, Mallick S, Skoglund P, Patterson N, Rohland N, Lazaridis I, Nickel B, et al. 2015. An early modern human from Romania with a recent Neanderthal ancestor. Nature 524:216-219.

Fu Q, Li H, Moorjani P, Jay F, Slepchenko SM, Bondarev AA, Johnson PLF, Aximu-Petri A, 
Prufer K, de Filippo C, et al. 2014. Genome sequence of a 45,000-year-old modern human from western Siberia. Nature 514:445-449.

Heaton TJ, Blaauw M, Blackwell PG, Bronk Ramsey C, Reimer PJ, Scott ME. 2020a. The IntCal20 approach to radiocarbon calibration curve construction: a new implementation using Bayesian splines and errors-in-variables. Radiocarbon 62. This issue.

Heaton TJ, Köhler P, Butzin M, Bard E, Reimer RW, Austin WEN, Ramsey CB, Grootes PM, Hughen KA, Reimer PJ, et al. 2020b. Marine20the marine radiocarbon age calibration curve (0-55,000 cal BP). Radiocarbon 62. This issue.

Higham T, Douka K, Wood R, Ramsey CB, Brock F, Basell L, Camps M, Arrizabalaga A, Baena J, Barroso-Ruiz C, et al. 2014. The timing and spatiotemporal patterning of Neanderthal disappearance. Nature 512:306-309.

Hoffman DL, Beck JW, Richards DA, Smart PL, Singarayer JS, Ketchmak T, Hawkesworth CJ. 2010. Towards radiocarbon calibration beyond 28 ka using speleothems from the Bahamas. Earth and Planetary Science Letters 289:1-10.

Höflmayer F. 2012. The date of the Minoan Santorini eruption: quantifying the "offset". Radiocarbon 54:435-448.

Hogg A, Southon J, Turney C, Palmer J, Bronk Ramsey C, Fenwick P, Boswijk G, Buntgen U, Froedrich M, Helle G, et al. 2016. Decadally resolved Lateglacial radiocarbon evidence from New Zealand Kauri. Radiocarbon 58:709-733.

Hogg A, Heaton TJ, Hua Q, Bayliss A, Blackwell PG, Boswijk G, Ramsey CB, Palmer J, Petchey F, Reimer P, et al. 2020. SHCal20 Southern Hemisphere calibration, 0-55,000 years cal BP. Radiocarbon 62. This issue.

Hublin JJ. 2012. The earliest modern human colonization of Europe. PNAS Commentary.

Hublin JJ, Talamo S, Julien M, David F, Connet N, Bodu P, Vandermeersch B, Richards MP. 2012. Radiocarbon dates from the Grotte du Renne and Saint-Césaire support a Neandertal origin for the Châtelperronian. Proceedings of the National Academy of Sciences 109:18743-18748.

Hughen KA, Lehman S, Southon J, Overpeck J, Marchal O, Herring C, Turnbull J. $2004 .{ }^{14} \mathrm{C}$ activity and global carbon cycle change over the past 50,000 years. Science 303:202-207.

Hughen KA, Southon JR, Lehman SJ, Bertrand CJH, Turnbull J. 2006. Marine-derived ${ }^{14} \mathrm{C}$ calibration and activity record for the past 50,000 years from thr Cariaco basin. Quaternary Science Reviews 25:3216-3227.

ISG. 1982. An inter-laboratory comparison of radiocarbon measurements in tree rings International Study Group. Nature 298:619-623.

ISG. 1983. An international tree-ring replicate study. In: Waterbolk HT, Mook WG, editors. Strasbourg. Pact 8:123-133.
Kaiser KF, Friedrich M, Miramont C, Kromer B, Sgier M, Schaub M, Boeren I, Remmele S, Talamo S, Guibal F, et al. 2012. Challenging process to make the Lateglacial tree-ring chronologies from Europe absolute-an inventory. Quaternary Science Reviews 36:78-90.

Kitagawa H, van der Plicht J. 1998. Atmospheric radiocarbon calibration to 45,000 yr BP: late glacial fluctuations and cosmogenic isotope production. Science 279:1187-1190.

Kitagawa H, van der Plicht J. 2000. Atmospheric Radiocarbon calibration beyond 11,900 cal BP from Lake Suigetsu laminated sediments. Radicoarbon 42:369-380.

Köhler P, Fischer H, Munhoven G, Zeebe RE. 2005. Quantitative interpretation of atmospheric carbon records over the last glacial termination. Global Biogeochem. Cycles 19, GB4020. doi: 10.1029/2004GB002345.

Köhler P, Muscheler R, Fischer H. 2006. A modelbased interpretation of low-frequency changes in the carbon cycle during the last 120,000 years and its implications for the reconstruction of atmospheric $\Delta^{14} \mathrm{C}$. Geochem. Geophys. Geosyst. 7, Q11N06. doi: 10.1029/2005GC001228.

Köhler P, Fischer H. 2004. Simulating changes in the terrestrial biosphere during the last glacial/ interglacial transition. Global Planetary Change 43: 33-55. doi: 10.1016/j.gloplacha.2004.02.005.

Köhler P, Fischer H. 2006. Simulating low frequency changes in atmospheric $\mathrm{CO}_{2}$ during the last 740000 years. Climate of the Past 2:57-78. doi: 10.5194/cp-2-57-2006.

Kromer B, Ambers J, Baillie MGL, Damon PE, Hesshaimer V, Hofmann J, Jöris O, Levin I, Manning SW, McCormac FG, et al. 1996. Report: Summary of the workshop "Aspects of high-precision radiocarbon calibration". Radiocarbon 38:607-610.

Kromer B, Friedrich M, Hughen KA, Kaiser KF, Remmele S, Schaub M, Talamo S. 2004. Late Glacial ${ }^{14} \mathrm{C}$ ages from a floating, 1382-ring pine chronology. Radiocarbon 46:1203-1209.

Kuitems M, van der Plicht J, Jansma E. 2020. Wood from the Netherlands around the time of the Santorini eruption dated by dendrochronology and radiocarbon. Radiocarbon 62. This issue.

Kutschera W, Bietak M, Wild EM, Bronk Ramsey C, Dee M, Golser R, Kopetzky K, Stadler P, Steier P, Thanheiser U, et al. 2012. The chronology of Tell el-Daba: a crucial meeting point of ${ }^{14} \mathrm{C}$ dating, archaeology and Egyptology in the 2nd millennium BC. Radiocarbon 54:407-422.

Lévêque F, Vandermeersch B. 1980. Découverte des restes humains dans un niveau castelperronien à Saint-Césaire (Charente-Maritime). CompteRendus de l'Académie des Sciences 291:187-189.

Manning S. 2014. A test of time and a test of time revisited: The volcano of Thera and the chronology and history of the Aegean and East 
Mediterranean in the mid-second millennium BC. Oxford/Philadelphia: Oxbow. 494 p. ISBN 9781782972198.

McAneney J, Baillie M. 2019. Absolute tree-ring dates for the Late Bronze Age eruptions of Aniakchak and Thera in light of a proposed revision of ice-core chronologies. Antiquity 93: 99-112.

Mellars P. 2006. A new radiocarbon revolution and the dispersal of modern humans in Eurasia. Nature 439:931-935.

Miyake F, Nagaya K, Masuda K, Nakamura T. 2012. A signature of cosmic-ray increase in AD 774-775 from tree rings in Japan. Nature 486:240-242.

Miyake F, Masuda K, Nakamura T. 2013. Another rapid event in the carbon-14 content of tree rings. Nature Communications 4. doi: 10.1038/ ncomms 2783 .

Mook WG, van der Plicht J. 1999. Reporting ${ }^{14} \mathrm{C}$ activities and concentrations. Radiocarbon 41: 227-239.

Müller UC, Pross J, Tzedakis PC, Gamble C, Kotthoff U, Schmiedl G, Wulf S, Christanis K. 2011. The role of climate in the spread of modern humans into Europe. Quaternary Science Reviews 30:273-279.

Muscheler R, Adolphi F, Heaton TJ, Bronk Ramsey C, Svensson A, van der Plicht J, Reimer PJ. 2020. Testing and improving the IntCal20 calibration curve with independent records. Radiocarbon 62. This issue.

Pearson CL, Brewer PW, Brown D, Heaton TJ, Hodgins GWL, Jull AJT, Lange T, Salzer MW. 2018. Annual radiocarbon record indicates 16th century BCE date for the Thera eruption. Science Advances 4:eaar8241.

Pearson CL, Wacker L, Bayliss A, Brown DM, Salzer MW, Brewer PW, Bollhalder S, Boswijk G, Hodgins GWL. 2018. Annual variation in atmospheric ${ }^{14} \mathrm{C}$ between $1700 \mathrm{BC}$ and 1480 BC. Radiocarbon 62. This issue.

Pearson GW, Stuiver M. 1986. High-precision calibration of the radiocarbon timescale 500-2500 BC. Radiocarbon 28:839-862.

Ralph EK, Michael HN, Han MC. 1973. Radiocarbon dates and reality. Masca Newsletter 9:1-20.

Rasmussen SO, Bigler M, Blockley SP, Blunier T, Buchardt SL, Clausen HB, Cvijanovic I, DahlJensen D, Johnsen SJ, Fischer H, et al. 2014. A stratigraphic framework for abrupt climatic changes during the Last Glacial period based on three synchronized Greenland ice-core records: refining and extending the INTIMATE event stratigraphy. Quaternary Science Reviews 106:14-28.

Reimer PJ, Baillie MGL, Bard E, Bayliss A, Beck JW, Bertrand CJH, Blackwell PG, Buck CE, Burr GS, Cutler KB, et al. 2004. INTCAL04 terrestrial radiocarbon age calibration, 0-26 cal kyr BP. Radiocarbon 46:1029-1058.
Reimer PJ, Baillie MGL, Bard E, Bayliss A, Beck JW, Blackwell PG, Bronk Ramsey C, Buck CE, Burr GS, Edwards RL, et al. 2009. IntCal09 and Marine09 radiocarbon calibration curves, 0-50 cal kBP. Radiocarbon 51:1111-1150.

Reimer PJ, Bard E, Bayliss A, Beck JW, Blackwell PG, Bronk Ramsey C, Buck CE, Cheng H, Edwards RL, Friedrich M, et al. 2013. IntCal13 and Marine13 radiocarbon age calibration curves $0-50,000$ years cal BP. Radiocarbon 55:1869-1887.

Reimer PJ, Austin WEN, Bard E, Bayliss A, Blackwell P, Bronk Ramsey C, Butzin M, Edwards L, Friedrich M, Grootes PM, et al. 2020. The IntCal20 Northern Hemisphere radiocarbon calibration curve $(0-55 \mathrm{kcal} \mathrm{BP})$. Radiocarbon 62. This issue.

Reinig F, Sookdeo A, Esper J, Friedrich M, Helle G, Kromer B, Nievergelt D, Pauly M, Tegel W, Treydte K, et al. 2020. Illuminating IntCal during the Younger Dryas. Radiocarbon 62. This issue.

Renfrew C. 1999. Before civilization-the radiocarbon revolution and prehistoric Europe. Pimlico.

Scott EM, Naysmith P, Cook GT. 2018. Why do we need ${ }^{14} \mathrm{C}$ inter-comparisons?: the Glasgow ${ }^{14} \mathrm{C}$ inter-comparison series, a reflection over 30 years. Quaternary Geochronology 43:72-82.

Southon J, Noronha AL, Cheng H, Lawrence Edwards R, Wang Y. 2012. A high resolution record of atmospheric ${ }^{14} \mathrm{C}$ based on Hulu Cave speleothem H82. Quaternary Science Reviews 33:32-41.

Stohl A, Bonasoni P, Cristofanelli P, Collins W, Feichter J, Frank A, Forster C, Gerasopoulos E, Gäggeler H, James P, et al. 2003. Stratospheretroposphere exchange: A review, and what we have learned from STACCATO. Journal of Geophysical Research Atmospheres 108(D12). doi: 10.1029/2002/JD002490.

Stuiver M, Polach H. 1977. Discussion: Reporting of ${ }^{14}$ C. Radiocarbon 19:355-363.

Stuiver M. 1982. A high precision calibration of the $\mathrm{AD}$ radiocarbon time scale. Radiocarbon 24:1-26.

Stuiver M, Pearson GW. 1986. High-precision calibration of the radiocarbon timescale $\mathrm{AD}$ 1950-500 BC. Radiocarbon 28:805-838.

Suess HE. 1980. The Radiocarbon record in tree rings of the last 8000 years. Radiocarbon 22: 200-209.

Synal HA, Stocker M, Suter M. 2007. MICADAS: A new compact radiocarbon AMS system. Nuclear Instruments and Methods in Physics Research B 259:7-13.

Trinkaus E, Moldovan O, Milota S, Bîlgar A, Sarcina L, Athreya S, Bailey SE, Rodrigo R, Mircea G, Higham T, et al. 2003. An early modern human from the Pestera cu Oase, Romania. Proceedings of the National Academy of Sciences 100:11231-11236. 
van Andel TH. 2005. The ownership of time: Approved ${ }^{14} \mathrm{C}$ calibration or freedom of choice? Antiquity 79:944-948.

van der Plicht J. 2000. The 2000 radiocarbon varve/ comparison issue: Introduction. Radiocarbon 42:313-322.

van der Plicht J. 2004. Radiocarbon calibrationpast, present and future. Nuclear Instruments and Methods in Physics Research B 223-224:353-358.

van der Plicht J, Beck JW, Bard E, Baillie MGL, Blackwett PG, Buck CE, Friedrich M, Guilderson TP, Hughen KA, Kromer B, et al. 2004. NOTCAL04: Comparison/calibration ${ }^{14} \mathrm{C}$ records 26-50 cal kyr BP. Radiocarbon 46:1225-1238.

Vogel JC, Kronfeld J. 1997. Calibration of Radiocarbon dates for the Late Pleistocene using U/Th dates on stalagmites. Radiocarbon 39:27-32.
Wacker L, Scott EM, Bayliss A, Brown D, Bard E, Bollhalder S, Friedrich M, Capano M, Cherkinsky A, Chivall D, et al. 2020. Findings from an in-depth annual tree ring radiocarbon intercomparison. Radiocarbon 62. This issue.

Welker F, Hajdinjak M, Talamo S, Jaouen K, Dannemann M, David F, Julien M, Meyer M, Kelso J, Barnes I, et al. 2016. Palaeoproteomic evidence identifies archaic hominins associated with the Châtelperronian at the Grotte du Renne. Proceedings of the National Academy of Sciences 113:11162-11167.

Weninger B, Jöris O. 2004. Glacial radiocarbon age calibration: The CalPal program. In: Higham T, Bronk Ramsey C, Owen C, editors. Radiocarbon and Archaeology, Volume Monograph 62. Oxford: St Catherine's College, Oxford University School of Archaeology. p. 9-15. 